\title{
Aspectos institucionales para potenciar la evaluación social de proyectos en transporte: lecciones de América Latina*
}

\author{
Andrés Gómez Lobo \\ Christian Belmar \\ Departamento de Economía \\ Universidad de Chile
}

\section{Resumen}

Este trabajo presenta una discusión en torno a los diseños institucionales que se pueden adoptar para potenciar la evaluación social de proyectos como instrumento que contribuya positivamente a la asignación de recursos en la economía. Esta discusión se basa en la experiencia latinoamericana, par ticularmente la de Chile con su Sistema Nacional de Inversiones. Entre los elementos que se destacan es la separación entre el ente proponente y el ente evaluador de los proyectos, y una base normativa fuerte que incluye el desarrollo de metodologías y procedimientos. Se hace una evaluación muy preli minar sobre la efectividad de los sistemas nacionales de inversión en mejorar la asignación de recur sos públicos. En el caso de Chile, la información disponible indicaría que este ha sido el caso, aun que se podría mejorar la retroalimentación de las evaluaciones ex-ante con evaluaciones ex-post e independizar las tareas de supervisión y evaluación del sistema.

Palabras clave: evaluación de proyectos, infraestructura.

Clasificación JEL: H11, H43, H54.

\begin{abstract}
This paper presents a discussion on the institutional safeguards that can be adopted to boost the use of cost benefit analysis as an instrument to improve resource allocation in the economy. This dis cussion is based on the experience of Latin America, in particular the case of Chile and its National Investment System. Among the highlighted elements is the separation between project proponent and evaluating agency, and a strong normative base that includes procedures and methodologies for pro ject evaluation. A preliminary evaluation is undertaken of the effectiveness of national investment sys tems to improve allocation of public funds. In the case of Chile, the available evidence indicates that the system has had a positive impact, although the system could be improved by a better feedback of ex-ante evaluation from ex-post evaluations and by assigning the supervision and evaluation of the sys tem to an independent body.
\end{abstract}

Keywords: project evaluation, infrastructure.

JEL Classification: H11, H43, H54.

* Se agradece la información provista por Silvia Montevilla y Nancy Whittle de Mideplan (Chile), Chrisitian Borja, Artura Ardila-Gómez y José Barbero del Banco Mundial. Naturalmente, las opiniones, errores y omisiones en este documento son de exclusiva responsabilidad de los autores y en nada comprometen a estas personas o las instituciones que representan. 


\section{Introducción}

La evaluación social de proyectos tiene el potencial de ser una herramienta muy útil para la toma de decisiones de inversión en el sector público y así garantizar la eficiente asignación de los recursos en la economía. Sin embargo, al ser generalmente aplicada ex-ante en la etapa de pre-inversión de los proyectos, sus resultados dependen de una serie de supuestos y proyecciones de demanda y de costes, además de parámetros de precios sociales, difíciles de objetivar. Por esto, las evaluaciones pueden ser manipuladas consciente o inconscientemente (sesgo optimista) para obtener cualquier resultado deseado.

En este contexto existe el riesgo de que una institución pública no utilice correctamente esta herramienta, considerándola sólo un obstáculo burocrático a sortear antes de poder ejecutar un proyecto que, de antemano, ha determinado es conveniente realizar. Cuando esto ocurre, la evaluación social de proyectos pierde su utilidad como herramienta de decisión y como garantía de un uso adecuado de los recursos públicos.

Este trabajo presenta una discusión en torno a los diseños institucionales que se pueden adoptar para reducir el riesgo identificado anteriormente y así potenciar la evaluación social de proyectos como instrumento que contribuya positivamente a la asignación de recursos en la economía. Esta discusión se basa en la experiencia latinoamericana, particularmente la de Chile con su Sistema Nacional de Inversiones. Durante las últimas décadas casi todos los países de América Latina han desarrollado Sistemas Nacionales de Inversión Pública (SNIP), aunque el grado de desarrollo e institucionalización de estos sistemas difiere de país a país ${ }^{1}$. El objetivo de los SNIP es proveer un marco coherente para identificar, coordinar, evaluar y ejecutar las inversiones públicas, siendo uno de sus objetivos prioritarios el mejorar la asignación de recursos mediante una adecuada evaluación social de las iniciativas de inversión. Generalmente estos sistemas están asociados a un 'banco de proyectos', herramienta informática que permite clasificar, evaluar y dirigir todos los proyectos de inversión propuestos para ser financiados con fondos públicos.

Los SNIP más desarrollados tienen varias características institucionales interesantes de destacar. Por ejemplo, homogenizan los formatos de presentación de los proyectos, desarrollan procesos explícitos de preparación y evaluación ex-ante, introducen manuales metodológicos de aplicación general y definen una institución evaluadora distinta de la institución que promueve o ejecuta un proyecto, entre otras. Discutir si estas características sirven o no para fortalecer la evaluación social de proyectos es justamente el objetivo del presente trabajo.

En la siguiente sección se describe el SNIP de Chile, el más antiguo y desarrollado de la región, para luego extraer los elementos más interesantes que podrían considerar-

\footnotetext{
${ }^{1}$ Una definición de un SNIP es «un conjunto de normas, instrumentos y procedimientos comunes para el sector público y entidades del sector privado que ejecuten inversión pública (ONG), mediante los cuales se relacionan y coordinan entre sí, para preparar, evaluar, priorizar, financiar, dar seguimiento y ejecutar los proyectos de inversión pública, en el marco de las políticas, planes y programas de desarrollo» (ORTEGA y PACHECO, 2004, pág. 13).
} 
se como recomendables para un sistema de evaluación social de proyectos. Luego, con esos elementos como benchmark, se describen las prácticas de evaluación en otros países de la región. En muchos de ellos se han desarrollado SNIP que replican algunos de los elementos del sistema chileno, pero donde además cobra importancia la contraparte técnica de los organismos multilaterales, como el Banco Mundial y el BID.

\section{EI SNI de Chile}

Si bien los orígenes del SNI en Chile datan de los años cincuenta, fue en la década de los años ochenta donde el sistema adquirió su estructura actual. En Chile, por Ley, todo ente público, sea este un ministerio, gobierno regional, municipio, empresa o servicio público, que quiera ejecutar un proyecto o programa de inversión, incluyendo los estudios de base requeridos, debe presentar una petición al Sistema Nacional de Inversiones (SNI) ${ }^{2}$, para su evaluación ${ }^{3}$. Sólo aquellas iniciativas que han sido evaluadas podrán ejecutarse ${ }^{4}$. En el caso de estudios de perfil o pre-factibilidad, se requiere una evaluación para que el proyecto continúe a las etapas siguientes de desarrollo. Este procedimiento aplica también a los proyectos de infraestructura concesionada, donde los privados financian la inversión.

Las etapas que debe cumplir cada proyecto en el SNI dependen de la complejidad técnica y los costos de los mismos. Para proyectos menores, la evaluación positiva del perfil del proyecto puede ser suficiente para comenzar su ejecución, mientras que para proyectos más complejos o de mayor costo, se requiere una evaluación de la iniciativa en cada una de sus etapas (perfil, pre-factibilidad, factibilidad y diseño) antes de poder ser ejecutado. Para proyectos intermedios, la evaluación puede circunscribirse a la etapa de factibilidad y diseño solamente.

Institucionalmente, la actividad de evaluación ex-ante y ex-post de las iniciativas de inversión del SNI está radicada en el Ministerio de Planificación (MIDEPLAN) quien tiene la función de a) regular los procedimientos para la formulación, prepa-

${ }^{2}$ El SNI es un SNIP, pero como en Chile se utilizan estas siglas para denominar su SNIP en esta sección se usa esta nomenclatura.

${ }^{3}$ El artículo 19bis de la Ley 1.263 (Ley Orgánica de la Administración del Estado) señala que «Los estudios preinversionales y los programas o proyectos de inversión deberán contar, como documento interno de la Administración, con informe del organismo de planificación nacional o regional en su caso, el cual deberá estar fundamentado en una evaluación técnica económica que analice su rentabilidad». En el caso de las inversiones realizadas con financiamiento del Fondo Nacional de Desarrollo Regional, la normativa es más estrictica y exige no solo un análisis de rentabilidad sino que una recomendación favorable del organismo evaluador.

${ }^{4}$ La única excepción son las iniciativas de inversión de las Fuerzas Armadas, que no requieren pasar por este proceso, aunque recientemente el Ministerio de Defensa ha desarrollado un sistema paralelo de evaluación de inversiones, análogo al SNI. Por otro lado, hay proyectos que podrían calificarse como inversión pero que formalmente para los fines de someterlos al SNI no lo son (por ejemplo, proyectos de formación de capital humano, conservación o gastos de mantención de infraestructura, etc.). Utilizando una definición amplia de inversión, DIPRES (2007) estima entre un 60 por 100 y 68 por 100 la inversión pública anual materializada entre los años 2003 y 2006 pasó por el SNI. 
ración y evaluación de los proyectos que aspiran a la financiación pública, b) mantener el Banco Integrado de Proyectos (BIP), c) desarrollar las metodologías de preparación y evaluación de proyectos, incluyendo la determinación de los precios sociales, y d) capacitar a los funcionarios públicos en la formulación, preparación y evaluación de los proyectos (Mideplan, 2009a) ${ }^{5}$. Algunas de las funciones anteriores, particularmente la de establecer las Normas, Instrucciones y Procedimientos (NIP) del SNI, son desarrolladas en conjunto con la Dirección de Presupuestos (DIPRES) del Ministerio de Hacienda. También participa dentro del contexto de normativa y control, la Contraloría General de la República.

\subsection{Proceso de un proyecto dentro del Sistema}

El Gráfico 1 presenta un diagrama con el flujo de un proyecto en el SIN ${ }^{6}$. En ocasiones la institución que formula el proyecto no es la institución que financia el proyecto en términos formales. Este es el caso, por ejemplo, de los proyectos formulados

GRÁFICO 1

FLUJO DE UN PROYECTO EN EL SIN

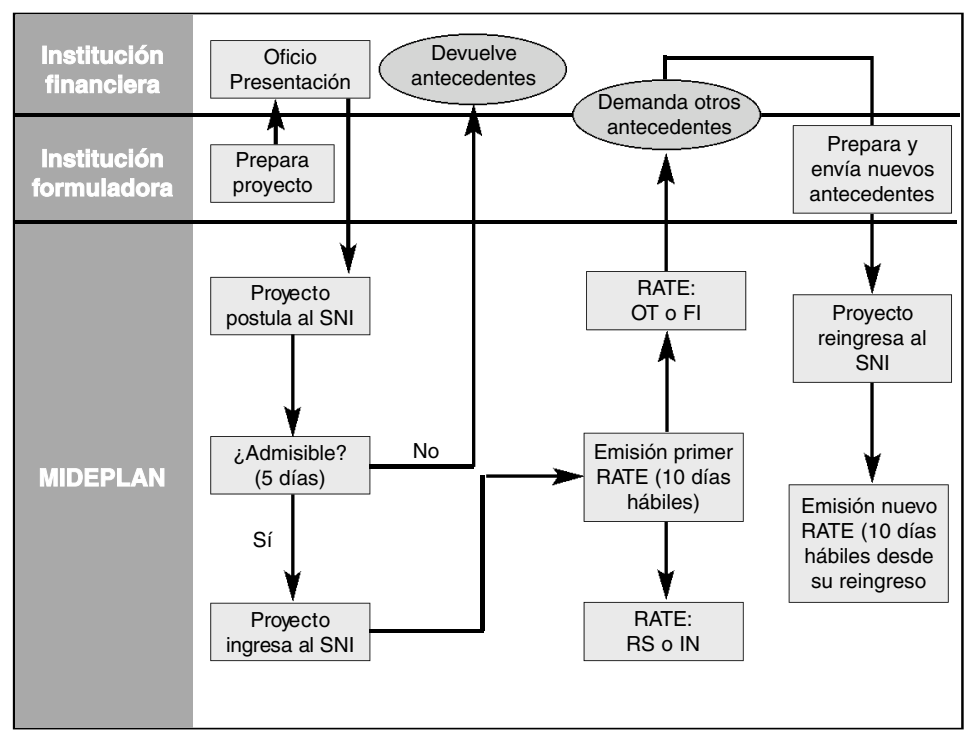

FUENTE: MIDEPLAN (2009A).

5 Aunque MIDEPLAN también debe realizar evaluaciones ex-post a una muestra representativa de estudios, proyectos y programas financiados por los gobiernos regionales, la presente discusión está enfocada en la evaluación ex-ante de las iniciativas de inversión.

6 Cabe destacar que en la actualidad cerca del 95 por 100 de las iniciativas de inversión son analizadas en las oficinas regionales de Mideplan y no a nivel central. Este hecho constituye uno de los principales cambios acontecidos en el sistema en los últimos años. Lo anterior implicó por tanto, fortalecer las capacidades regionales para llevar a cabo la evaluación de proyectos. 
por los gobiernos locales (municipios) pero que buscan ser financiados por el Fondo Nacional de Desarrollo Regional (FNDR) que administran los gobiernos regionales.

La institución formuladora debe recopilar todos los antecedentes del proyecto, incluyendo una evaluación social del mismo, verificar que se cumplen las normas del SNI, verificar que la iniciativa de inversión no esté duplicada en el sistema de inversiones y generar la ficha de solicitud de financiación (ficha IDI) en el Banco Integrado de Proyectos (BIP) ${ }^{7}$. Con estos antecedentes, y luego de confirmar que se cuenta con el marco presupuestario correspondiente, la institución financiera presenta el dossier a Mideplan para la solicitud al SNI. A partir de esta fecha, Mideplan asigna un Analista de Inversión al proyecto quien tiene cinco días hábiles para determinar si la iniciativa es o no admisible. Los criterios de admisibilidad son básicamente que los antecedentes y la información del proyecto esté completa y permita su evaluación, y algunos criterios administrativos respecto a la forma en que se presentó el proyecto (ficha IDI, marco presupuestario suficiente de la autoridad financiera, oficio conductor, etc.).

Una vez que el proyecto haya sido declarado admisible, ingresa formalmente en el SNI. Esto se materializa poniendo la «fecha de solicitud» en la ficha del proyecto en el BIP. Luego, un analista de inversiones de Mideplan revisa los antecedentes y se constata la evaluación social del proyecto evaluado. Dentro de diez días hábiles desde la fecha de solicitud, Mideplan entrega el «Resultado de Análisis TécnicoEconómico» (RATE) que puede ser uno de los siguientes (Mideplan, 2009a):

- RS (Recomendado favorablemente): el proyecto cumple los requisitos y normas del SNI, incluyendo el de ser la mejor alternativa para el problema identificado. En el caso que la evaluación sea de «coste beneficio», la TIR del proyecto debe ser superior al umbral definido anualmente por Mideplan para obtener RS. Cuando se trata de un análisis «coste efectividad», el proyecto definido debe ser el de menor coste social entre las alternativas factibles.

- FI (Falta información): falta información técnica, legal o de otra índole para calificar el proyecto.

- IN (Incumplimiento de normativa): cuando a un proyecto ya se le asignó presupuesto, comenzó su ejecución o desarrollo, sin contar con una recomendación favorable, entonces Mideplan no califica el proyecto ${ }^{8}$. Esto también aplica a proyectos originalmente aprobados pero que posteriormente sufrieron un cambió de naturaleza, magnitud, costes, o plazos sin haber sido comunicado a Mideplan.

- OT (Objetado técnicamente): proyecto no es socialmente rentable (según umbral definido anualmente por Mideplan, no es técnicamente viable o está mal formulado, o no se ajusta a las políticas definidas para el sector, entre otras.

\footnotetext{
7 IDI: Iniciativa de Inversión. Esta ficha se denominaba EBI (Estadísticas Básicas de Inversión) hasta hace poco años atrás.

8 En este caso, es responsabilidad de la Contraloría General de la República indagar si hubo irregularidades al haberse asignado presupuesto o comenzado la ejecución de un proyecto sin contar con una evaluación técnica económica.
} 
En caso de que falte información (FI) o el proyecto es objetado técnicamente (OT), la institución financiera y la institución formuladora pueden presentar más antecedentes y reingresar el proyecto al sistema, para lo cual Mideplan dispone de 10 días hábiles para emitir un nuevo RATE ${ }^{9}$.

De acuerdo Dipres (2007) en la evaluación técnica-económica de los proyectos trabajan cerca de 214 profesionales en términos de jornadas equivalentes, incluyendo los profesionales de Mideplan como de las oficinas regionales (SERPLAC) de este Ministerio, y se gasta en evaluación en promedio cerca de 400 dólares US por iniciativa ${ }^{10}$. La misma fuente señala que en el año 2006 se evaluaron 12.730 iniciativas de inversión. La tasa de iniciativas con RS (Recomendada Socialmente) ha fluctuado entre un 52 por 100 y 59 por 100 de las iniciativas de inversión ingresadas al sistema cada año (Dipres, 2007).

\section{Características institucionales interesantes del SNI de Chile}

Luego de la breve descripción del SNI de Chile, en esta sección se presentan algunas características institucionales importantes que son interesantes de resaltar, ya que constituyen elementos que potencialmente son replicables en otros países. Posteriormente en este trabajo se revisará cuáles de las características discutidas están también presentes en los sistemas nacionales de inversión de otros países.

\subsection{Obligatoriedad legal del proceso de evaluación}

Un primer elemento que es importante resaltar es la obligatoriedad legal de evaluar socialmente todos los proyectos de inversión y programas del sector público, incluso aquellos con financiación privada, como el caso de las concesiones de obras públicas. Este es un primer requisito que garantiza que todo proyecto tenga una evaluación social. Sin embargo, no garantiza la calidad ni la seriedad con que se realizan dichas evaluaciones. Tampoco se requiere necesariamente un RATE favorable (RS) para ejecutar un proyecto, salvo aquellos financiados por el FNDR, pero sí requiere pasar por el proceso de evaluación.

\subsection{La separación institucional entre proponente y evaluador}

Un segundo elemento importante a destacar es la separación entre la institución proponente de un proyecto y la institución evaluadora, de forma tal que no generan

\footnotetext{
${ }^{9}$ DIPRES (2007) estima que un proyecto en promedio requiere entre 4 o 5 iteraciones antes de obtener un RATE favorable.

10 Según DIPRES (2007), en el año 2006 se gastaron 226.000 pesos chilenos por iniciativa, lo cual corresponde a la cifra indicada en el texto a un tipo de cambio de 506 dólares.
} 
conflictos de intereses. Es habitual que una institución promotora de proyectos (como podría ser un Ministerio de Obras Públicas) tenga como principal función objetivo maximizar el número y cuantía de los proyectos realizados. En un escenario así, podría descuidarse la evaluación rigurosa de los mismos.

Al crear una institución especializada en la evaluación de los proyectos, se pueden desarrollar capacidades técnicas específicas, estandarizar procedimientos y metodologías, y centralizar la información histórica de muchos proyectos y sectores de la economía, información que sirve para refinar la estimación de costes y beneficios de los futuros proyectos evaluados.

Pero lo más importante es que los funcionarios encargados de evaluar los proyectos, no responden jerárquicamente a la autoridad proponente de los proyectos, por lo que tienen un grado mayor de autonomía e independencia para evaluar objetivamente las propuestas. Además, la autoridad que dirige la institución evaluadora (en el caso de Chile, Mideplan), tiene otros objetivos que las instituciones promotoras. Por ejemplo, la de garantizar la calidad de las evaluaciones sociales de los proyectos y velar por la eficiente asignación de los recursos públicos.

La independencia y autonomía de la institución evaluadora no es absoluta, ya que tanto los funcionarios de Mideplan como de otros Ministerios y entes públicos depende jerárquicamente de la autoridad política de turno. Pero sí permite disminuir las presiones políticas y jerárquicas que podrían afectar la calidad de las evaluaciones cuando el ente proponente es también el ente evaluador.

\subsection{Evaluación multietapa y con varios filtros y mecanismos de supervisión}

Otra característica del SNI de Chile que parece interesante destacara es la evaluación en varias etapas, con varios filtros y mecanismos de supervisión.

Un proyecto de inversión grande, como podría ser un puente, una carretera u otra obra de infraestructura de transportes, requiere ser evaluado en todas sus etapas de proyecto (perfil, prefactibilidad, factibilidad y diseño) antes de poder ser ejecutado. Esto permite ir corrigiendo errores u omisiones en las etapas previas. Cualquier modificación del proyecto original será evaluada en sus etapas posteriores. Por otro lado, cuando un proyecto en ejecución tiene un sobrecoste superior al 10 por 100 de la inversión (privada) presupuestada debe volver al sistema para su re-evaluación ${ }^{11}$.

El SNI en Chile contempla además otros mecanismos de supervisión y control de calidad. Por ejemplo, hay una separación entre el profesional que analiza los pro-

11 Debido a que una parte de la inversión del proyecto ya está realizada, es poco frecuente que la modificación no sea socialmente rentable. Sin embargo, este proceso permite analizar la pertinencia y justificación de los sobrecostes, lo cual agrega un filtro adicional para que los promotores o ejecutores de una iniciativa no cambien el proyecto original, salvo por razones justificadas. Muchas veces los sobrecostes tienen relación con cambios en los precios de los insumos entre el momento en que el proyecto obtuvo un RATE favorable y el momento en que comienza su ejecución. 
yectos y aquel que tienen la responsabilidad de asignarle la RATE. Esto permite que los proyectos sean revisados por más de un profesional, aunque en la práctica el segundo analista se limita más bien a revisar aspectos formales de la ficha del proyecto y asegurar su consistencia. Por otro lado, en el caso de iniciativas de inversión que por su naturaleza resultan difíciles de evaluar en términos metodológicos, Mideplan suele formar un comité de analistas para su evaluación.

Por último, dos o tres veces al año Midpelan realiza un proceso de revisión de una muestra aleatoria de iniciativas de inversión que obtuvieron una calificación de RS. Según Dipres (2007), en el año 2006 un 15 por 100 de los proyectos con RS revisados no cumplían con los criterios técnicos para su recomendación favorable ${ }^{12}$.

\subsection{Normas, procedimientos y metodologías establecidas ex-ante.}

Por otro lado, también es interesante destacar que el SNI tiene normas, procedimientos y metodologías generales establecidas ex-ante. Esto permite homogeneizar la forma de presentar la información de los proyectos y programas, facilitando su comparación. También permite que los proyectos puedan ser evaluados utilizando técnicas validadas y comúnmente aceptadas por la profesión.

En el tema de las metodologías cabe destacar que Mideplan produce manuales metodológicos de evaluación para los distintos tipos de proyectos ${ }^{13}$. Aparte de un manual de Metodología General de Preparación y Evaluación de Proyectos, hay veintiocho manuales específicos por tipos de proyecto. En el caso de transportes, el siguiente cuadro muestra los manuales metodológicos actualmente en uso ${ }^{14}$. Los proyectos que postulan al financiamiento del SNI en cada categoría deben presentarse y evaluarse según lo que se establece en cada reglamento.

\footnotetext{
12 Según la misma fuente, en el año 2003 esta proporción fue de un 20 por 100. Según Mideplan (entrevista a Nancy Whittle), dicha proporción habría disminuido al 7 por 100 en el año 2009, y señala que estas discrepancias se originan, en general, por diferencias de criterios entre el analista original del proyecto y los supervisores.

13 Todos los manuales están disponibles en la web http://sni.mideplan.cl/.
} 


\section{CUADRO 1}

\section{MANUALES OFICIALES DE METODOLOGÍAS DE PREPARACIÓN Y EVALUACIÓN SOCIAL DE PROYECTOS EN EL SECTOR TRANSPORTE EN CHILE}

\begin{tabular}{|c|}
\hline Metodología de Preparación y Evaluación de Proyectos de Aeropuertos \\
\hline Metodología de Evaluación Económica de Caminos de Bajo Estándar \\
\hline Metodología de Preparación y Evaluación de Proyectos de Mejoramiento Vial Urbano \\
\hline $\begin{array}{c}\text { Instructivo para la Preparación y Evaluación de Vías Urbanas y Caminos Interurbanos en Comunas } \\
\text { Pobres del País }\end{array}$ \\
\hline Metodología de Preparación y Evaluación de Proyectos de Pequeños Aeródromos \\
\hline Metodología de Preparación y Evaluación de Proyectos de Transporte Interurbano \\
\hline Metodología de Preparación y Evaluación de Proyectos de Vialidad Intermedia \\
\hline Metodología de Proyectos de Viabilidad Urbana \\
\hline
\end{tabular}

FUENTE: MIDEPLAN.

\subsection{Determinación centralizada de los precios sociales}

Relacionado con lo anterior, anualmente Mideplan estudia y revisa los precios sociales de la mano de obra (calificada, semi-calificada y no calificada), la divisa y la tasa de descuento, además de otros precios comúnmente utilizados en las evaluaciones. En el caso del transporte, por ejemplo, destaca la determinación de los precios sociales de los combustibles, lubricantes, neumáticos, vehículos nuevos, horas de manutención y el valor social del tiempo de viaje. Todas estas categorías están desagregadas por tipo de vehículo. A su vez el valor social del tiempo de viaje está separado entre viajes urbanos y viajes interurbanos ${ }^{15}$.

Hay evidentes economías de escala al determinar centralizadamente los precios sociales que aplican a muchos proyectos. Además, este procedimiento permite que los analistas que proponen y evalúan un proyecto puedan concentrarse en la evaluación propiamente tal y no destinar tiempo a la estimación de los precios sociales. Por otro lado, al tener precios sociales determinados centralizadamente, todos los proyectos se evalúan en igualdad de condiciones respecto a esta dimensión. No hay

\footnotetext{
${ }^{14}$ Podría llamar la atención que no exista un manual específico para proyectos de ferrocarriles. Sin embargo, en Chile el desarrollo de esta infraestructura es de menor importancia relativa que en otros países. En todo caso, existe un manual en desarrollo para este sector, pero cuyo uso aún no ha sido aprobado.

${ }^{15}$ Los precios sociales para los proyectos que representan para su financiación en el año 2011, se pueden consultar en http://sni.mideplan.cl/postulacion_links/77_precios_sociales2011.pdf.
} 
tampoco espacio para una modificación discrecional de los precios por parte de un analista.

\subsection{Evaluaciones ex-post}

El SNI también considera formalmente la evaluación ex-post de los proyectos. Estas evaluaciones permiten modificar y perfeccionar las metodologías de evaluación, y afinar los parámetros y supuestos utilizados en las evaluaciones ex-ante que se realizan en el futuro. Existen dos tipos de análisis ex-post, uno simplificado, que consiste en revisar los costes, plazos de ejecución y cumplimiento de las normativas técnicas, justo después del término de la ejecución del proyecto en cuestión, y uno en profundidad, donde además de las variables anteriores se revisa el logro de los beneficios y costos esperados después de un período razonable en que el proyecto ha estado operativa.

Anualmente Mideplan realiza una evaluación ex-post simplificada a una muestra representativa de proyectos, programas y estudios básicos financiados con el Fondo Nacional de Desarrollo Regional (FNDR) de los gobiernos regionales. Pero este proceso de evaluación ex-post sólo cubre los proyectos del FNDR y no las inversiones sectoriales ${ }^{16}$. Como se discutirá en la próxima sección, actualmente se están realizando esfuerzos para ampliar las evaluaciones ex-post simplificadas al universo de los proyectos ejecutados.

Por otro lado, las evaluaciones ex-post en profundidad son menos numerosas. Hasta la fecha se han realizado evaluaciones en el sector salud, energía, educación y transportes. Los resultados de estos estudios para el caso de proyectos de transportes se presentan más adelante en este trabajo.

\subsection{Sistema de información de proyectos centralizado y transversal}

El Banco Integrado de Proyectos (BIP) ofrece una plataforma única de información que aumenta la transparencia del sistema. La ficha de cada proyecto en el BIP contiene información de la iniciativa y puede ser modificada y actualizada por los proponentes del proyecto. Además, este sistema en línea, le permite a las instituciones que concurren al sistema de inversiones conocer rápidamente las observaciones realizadas a los proyectos por Mideplan y el RATE obtenido. El sistema también permite un acceso limitado para el público en general, lo que permite que éste se informe de las características generales de los proyectos de inversión.

Este sistema podría potencialmente ser la base de un análisis histórico de costes y de demanda de distintos tipos de proyectos y que permita una estimación más cer-

\footnotetext{
${ }^{16}$ Las inversiones del FNDR representan alrededor del 15 por 100 de la inversión pública total.
} 
tera de estas variables en evaluaciones futuras. Hasta el momento, la información del BIP en Chile no se ha utilizado de esta manera, y la 'información histórica' de los proyectos actualmente radicada informalmente en el personal de Mideplan. Sin embargo, se espera que a partir del 2011 se pueda cruzar la información del BIP con la información del Sistema Integrado de Gestión Financiera (SIGFA) del Ministerio de Hacienda que lleva los registros de los recursos efectivamente ejecutados en cada proyecto. De esta manera, se podrá contrastar la información de costos contenida en la evaluación ex-ante con lo efectivamente gastado en cada proyecto.

\section{Experiencia de otros países de la región}

En general todos los países de la región han establecido algún sistema nacional de inversión, aunque en muchos casos están guiados más hacia temas de planificación presupuestaria que de evaluación ex-ante de proyectos (Ortegon y Pacheco, 2004 y 2005; Ortegon y Dorado, 2006; Contreras, Cartes y Pacheco, 2010).

Los sistemas más antiguos y consolidados son los de Chile y Colombia. Otros países han avanzado recientemente en el desarrollo de sus sistemas, como el caso de Perú, Nicaragua, Guatemala, México y Argentina.

También ha habido algunas experiencias donde los sistemas no han operado según lo esperado, se han manifestado retrocesos y se ha hecho necesario «refundar» los SNIP, como en el caso de Ecuador, Costa Rica y República Dominicana (Contreras et al., 2010).

A continuación se comparan algunos elementos relacionados con el proceso de evaluación social implícito en los SNIP para los países de Perú, Argentina, Brasil, Colombia y México. En particular se presenta un cuadro comparativo, a partir del cual es posible desprender los siguientes aspectos ${ }^{17}$ :

Marco legal. Todos los sistemas cuentan para su funcionamiento con un marco legal con distinto grado de formalización. Sin embargo, el elemento central que destaca es que dichos marcos establecen que las iniciativas deben evaluarse antes de obtener financiación, o que las iniciativas sean implementadas. El instrumento normativo en su gran mayoría corresponde a la publicación de una ley donde se establece el SNIP, o una ley donde se establece una institucionalidad. En los sistemas estudiados, se aprecia que el objetivo de contar con una SNIP es contribuir a mejorar la eficiencia y calidad de la inversión pública, y por esta vía impulsar procesos de crecimiento económico.

Separación entre proponente y evaluador. Se aprecia que existe un reguardo con respecto al conflicto de interés que existe entre el evaluador y el proponente. En

\footnotetext{
${ }^{17}$ Este resumen se basa en CONTRERAS et al., (2010).
} 
general cuentan con una unidad de evaluación dependiente de algún Ministerio del orden económico, como es el caso del Ministerio de Hacienda. Este es un tema central a la hora de validar los SNIP como herramienta de apoyo a la toma de decisiones por parte de la autoridad.

Evaluación multietápica. La evaluación de iniciativas se realiza en distintas instancias o niveles de elaboración, esto es, generalmente se identifica la situación de proyectos en etapa de perfil, prefactibilidad, y factibilidad. De modo que existe un proceso de avance secuencial a nivel global para la obtención de financiamiento para las iniciativas.

Normas procedimientos, metodologías. Los SNIP cuentan con normativas para su funcionamiento. También establecen una programación para el proceso de inversión. Son sistemas donde se aprecia también esfuerzos de capacitación de los profesionales de las distintas instituciones que componen el sistema. En cuanto a las metodologías de evaluación, se observa que cuentan con metodologías de evaluación, que en algunos casos difieren por sector y se encuentran disponibles a través de las páginas web.

Precios sociales. En general existe un uso limitado de precios sociales en las evaluaciones de los proyectos en América Latina (Aldunate, 2010). Por ejemplo, no se utilizaban en las evaluaciones en el caso de la Provincia de Buenos Aires, y ciudades como Guanajuato en México y Tachirá en Venezuela (Ortegon y Pacheco, 2005). También era el caso de países como Costa Rica, El Salvador, Guatemala, Honduras, Nicaragua y Panamá, al menos a comienzos de la década pasada (Ortegón y Pacheco, 2004).

Evaluación ex-post. Es interesante notar que si bien este aspecto es de reconocida importancia, en la mayoría de los países la implementación de un sistema de evaluación ex-post aún se encuentra en fase de desarrollo, o bien, en el caso donde existe, aún debe ampliarse a un mayor número de iniciativas ejecutadas.

Banco Integrado de Proyectos. En general los SNIP cuentan con una Banco de Proyectos informatizados que apoya el proceso de inversión pública en diferentes grados, tales como: información, monitoreo y seguimiento, y construcción de estadísticas. 


\section{CUADRO 2}

\section{VISIÓN GENERAL DE LOS SISTEMAS NACIONALES DE INVERSIÓN PÚBLICA}

\begin{tabular}{|c|c|c|c|c|c|}
\hline Tema & Perú & Argentina & Brasil & Colombia & México \\
\hline $\begin{array}{l}\text { Marco legal } \\
\text { y/o obligato- } \\
\text { riedad legal } \\
\text { del proceso } \\
\text { de evalua- } \\
\text { ción }\end{array}$ & $\begin{array}{l}\text { Ley de creación, es } \\
\text { junio del 2000. Ante- } \\
\text { riormente, existió un } \\
\text { Instituto Nacional de } \\
\text { Planificación, desac- } \\
\text { tivado 1992. Ley } \\
\text { 26404, dispone la } \\
\text { creación de la Ofici- } \\
\text { na de Inversiones del } \\
\text { Ministerio de Econo- } \\
\text { mía y Finanzas } \\
\text { (ODI) }\end{array}$ & $\begin{array}{l}\text { Ley } 24.354 \text { supone } \\
\text { políticas nacionales y } \\
\text { sectoriales en materia } \\
\text { de inversión. } \\
\text { Decreto reglamenta- } \\
\text { rio n } \infty 720 \text { del } 1995 \text {. } \\
\text { Resoluciones de } \\
\text { Secretaría de Política } \\
\text { Económica }\end{array}$ & $\begin{array}{l}\text { Planificación Pública } \\
\text { Plurianual. } \\
\text { Ley de responsabili- } \\
\text { dad fiscal (año } \\
\text { 2000). } \\
\text { Constitución artículo } \\
\text { 165. (PPA-LDO- } \\
\text { LOA) }\end{array}$ & $\begin{array}{l}\text { Existe un conjunto } \\
\text { de normas, reglamen- } \\
\text { tos y leyes asociados } \\
\text { al funcionamiento } \\
\text { del sistema. }\end{array}$ & $\begin{array}{l}\text { Ley de Planeación. } \\
\text { Ley de Presupuesto } \\
\text { Federal. } \\
\text { Manual de normas } \\
\text { presupuestarias para } \\
\text { la administración } \\
\text { pública del año } 2002 \\
\text { Oficio de autorización } \\
\text { especial de inversión. } \\
\text { Oficio de inversión } \\
\text { financiada. } \\
\text { Oficio de autorización } \\
\text { de inversión. } \\
\end{array}$ \\
\hline $\begin{array}{l}\text { Etapas del } \\
\text { SNIP o del } \\
\text { procesos de } \\
\text { Inversión }\end{array}$ & $\begin{array}{l}\text { Preinversión: perfil, } \\
\text { prefactibilidad y fac- } \\
\text { tibilidad. } \\
\text { Inversión: expediente } \\
\text { técnico detallado y la } \\
\text { ejecución. } \\
\text { Postinversión: Com- } \\
\text { prende los procesos } \\
\text { de control y evalua- } \\
\text { ción } \text { ex-post }\end{array}$ & $\begin{array}{l}\text { Existe claridad con } \\
\text { respecto a las etapas } \\
\text { de Preinversión. }\end{array}$ & \begin{tabular}{|l|} 
Planificación \\
Ejecución \\
Monitoreo \\
Evaluación \\
Retroalimentación de \\
Programas
\end{tabular} & $\begin{array}{l}\text { Formulación } \\
\text { Programación } \\
\text { Ejecución } \\
\text { Seguimiento } \\
\text { Evaluación. } \\
\text { Dentro de la Etapa } \\
\text { de Formulación se } \\
\text { encuentra el BPIN }\end{array}$ & $\begin{array}{l}\text { Planeación } \\
\text { Análisis } \\
\text { Registro en Cartera } \\
\text { Programación y Pre- } \\
\text { supuesto } \\
\text { Ejecución } \\
\text { Seguimiento }\end{array}$ \\
\hline $\begin{array}{l}\text { Separación } \\
\text { entre propo- } \\
\text { nente y eva- } \\
\text { luador }\end{array}$ & $\begin{array}{l}\text { Existe la separación } \\
\text { entre institución for- } \\
\text { muladora, ejecutora, } \\
\text { financista. }\end{array}$ & $\begin{array}{l}\text { Existe separación } \\
\text { entre proponente y } \\
\text { evaluar. Hay organis- } \\
\text { mos dedicados a la } \\
\text { evaluación de las ini- } \\
\text { ciativas. }\end{array}$ & $\begin{array}{l}\mathrm{Si} \text {, para el caso de la } \\
\text { Planificación Pública } \\
\text { Plurianual hay una } \\
\text { estrategia de finan- } \\
\text { ciamiento, que es } \\
\text { diferente que quien } \\
\text { formula el proyecto. } \\
\end{array}$ & $\begin{array}{l}\text { Se identifica la uni- } \\
\text { dad que formula y la } \\
\text { unidad que evalúa } \\
\text { (deben ser distintas). }\end{array}$ & $\begin{array}{l}\text { Existe la separación } \\
\text { entre proponente y } \\
\text { ejecutor. (Unidad de } \\
\text { Inversiones al Inte- } \\
\text { rior del Ministerio de } \\
\text { Hacienda). }\end{array}$ \\
\hline $\begin{array}{l}\text { Evaluación } \\
\text { multi-etápi- } \\
\text { ca con } \\
\text { varios filtros } \\
\text { y mecanis- } \\
\text { mos de } \\
\text { supervición } \\
\end{array}$ & $\begin{array}{l}\text { Evaluación en distin- } \\
\text { tas etapas, de perfil, } \\
\text { prefactibilidad, facti- } \\
\text { bilidad. }\end{array}$ & & $\begin{array}{l}\text { Existe una gestión } \\
\text { integrada del Plan } \\
\text { Plurianual. }\end{array}$ & & $\begin{array}{l}\text { Evaluación en distin- } \\
\text { tas etapas, perfil, pre- } \\
\text { factibilidad. }\end{array}$ \\
\hline $\begin{array}{l}\text { Normas, } \\
\text { procedi- } \\
\text { mientos y } \\
\text { metodolo- } \\
\text { gías }\end{array}$ & $\begin{array}{l}\text { Existen normativas } \\
\text { y procedimiento con } \\
\text { respecto al desarrollo } \\
\text { de iniciativas. }\end{array}$ & $\begin{array}{l}\text { Existe guía para la } \\
\text { formulación y eva- } \\
\text { luación de proyectos } \\
\text { año } 1997 .\end{array}$ & $\begin{array}{l}\text { Hay criterios para la } \\
\text { evaluación de los } \\
\text { programas desarro- } \\
\text { llados. Y existe } \\
\text { manual de elabora- } \\
\text { ción de programas. }\end{array}$ & $\begin{array}{l}\text { Existe manual de } \\
\text { procedimientos. Así } \\
\text { como también meto- } \\
\text { dologías sectoriales. }\end{array}$ & $\begin{array}{l}\text { Se utilizan diferentes } \\
\text { metodologías: Análi- } \\
\text { sis costes beneficios, } \\
\text { Análisis coste efi- } \\
\text { ciencia. Justificación } \\
\text { económica. }\end{array}$ \\
\hline $\begin{array}{l}\text { Determina- } \\
\text { ción de pre- } \\
\text { cios sociales }\end{array}$ & Sin información. & $\begin{array}{l}\text { En general se entrega } \\
\text { las tasa social de des- } \\
\text { cuento y la tasa de } \\
\text { mano de obra. }\end{array}$ & Sin información. & $\begin{array}{l}\text { Se usan precios } \\
\text { sociales pero éstos } \\
\text { están muy desactuali- } \\
\text { zados (1990). }\end{array}$ & $\begin{array}{l}\text { Se proporciona la } \\
\text { tasa social de des- } \\
\text { cuento. }\end{array}$ \\
\hline $\begin{array}{l}\text { Evaluación } \\
\text { ex-post }\end{array}$ & $\begin{array}{l}\text { No hay aún un desa- } \\
\text { rrollo de éste ámbito }\end{array}$ & $\begin{array}{l}\text { Si bien existe la } \\
\text { intención de avanzar } \\
\text { en esta materia, aún } \\
\text { no se encuentra desa- } \\
\text { rrollado }\end{array}$ & $\begin{array}{l}\text { Existe una evalua- } \\
\text { ción de los progra- } \\
\text { mas cómo elementos } \\
\text { que permite la retroa- } \\
\text { limentación }\end{array}$ & $\begin{array}{l}\text { Existe una metodolo- } \\
\text { gía para la evaluación } \\
\text { ex-post de los proyec- } \\
\text { tos, tanto simplificada } \\
\text { (seguimiento) como } \\
\text { en profundidad. }\end{array}$ & $\begin{array}{l}\text { No se desarrolla un } \\
\text { sistema aún en esta } \\
\text { materia }\end{array}$ \\
\hline $\begin{array}{l}\text { Cuenta con } \\
\text { un Banco } \\
\text { Integrado de } \\
\text { proyectos o } \\
\text { sistemas de } \\
\text { información }\end{array}$ & $\begin{array}{l}\text { Existe un Banco de } \\
\text { Proyectos. }\end{array}$ & $\begin{array}{l}\text { El sistema cuenta } \\
\text { con un Banco de } \\
\text { Proyectos. En el año } \\
2003 \text { se implementó } \\
\text { la carga de proyectos } \\
\text { al BAPIN. }\end{array}$ & $\begin{array}{l}\text { Existe un banco de } \\
\text { proyectos que permi- } \\
\text { te obtener informa- } \\
\text { ción de las iniciati- } \\
\text { vas, ejecución, } \\
\text { presupuesto y segui- } \\
\text { miento (SIGPLAN) }\end{array}$ & $\begin{array}{l}\text { Existe un Banco } \\
\text { Integrado de Proyec- } \\
\text { tos denominado } \\
\text { BPIN. }\end{array}$ & $\begin{array}{l}\text { En sistema de infor- } \\
\text { mación y programas } \\
\text { y proyectos (SIPPI) } \\
\text { permite registrar y } \\
\text { procesar información } \\
\text { actualizada de las } \\
\text { iniciativas de inver- } \\
\text { sión pública. }\end{array}$ \\
\hline
\end{tabular}

FUENTE: CONTRERAS et al., (2010) y elaboración propia. 
A continuación se describen someramente los sistemas de cada uno de los países.

\subsection{SNIP de Colombia}

En el año 1989, se promulga la Ley 38, conocida como el Estatuto Orgánico del Presupuesto, que crea la estructura normativa del sistema nacional de inversiones de Colombia. El reglamento de esta Ley, Decreto N. ${ }^{\circ} 841$ de 1990, establece que «todos los proyectos de inversión que hayan de ser eventualmente financiados o cofinanciados con recursos del Presupuesto General de la Nación» (Artículo 1. ${ }^{\circ}$ ) serán evaluados técnica, económica y socialmente (Artículo 7. ${ }^{\circ}$ ). Quedan exceptuados «los proyectos de inversión para el apoyo regional autorizados por la ley y aquellos que se financien con recursos del Fondo de Compensación Interministerial que establece el artículo 70 de la Ley 38 de 1989 para los casos que el Presidente de la República y el Consejo de Ministros califiquen como de excepcional urgencia» (Artículo $1 .^{\circ}$ ). El mismo cuerpo legal determina la necesidad de establecer manuales de procedimientos y metodologías de evaluación y de seguimiento.

La normativa sitúa al Departamento Nacional de Planeación (DNP) como el encargado principal de las evaluaciones. Sin embargo, a diferencia de Chile donde existe una única institución que revisa los proyectos (Mideplan), en Colombia son los Ministerio, Departamentos Administrativos, Congreso, Órganos de Control, Rama Jurisdiccional quienes deben evaluar y determinar la «viabilidad» de los proyectos. Sin embargo, se establece que los proyectos deben ser revisados por una entidad distinta a la institución que lo remite al Banco de Proyectos (Artículos 10. ${ }^{\circ}$ y $12 .^{\circ}$ del Decreto N. ${ }^{\circ} 841$ de 1990). Por ejemplo, los proyectos originados en los Municipios serán revisados por las Oficinas de Planeación de los Departamentos, y aquellos originados en algún Ministerio, Departamento Administrativo Nacional, Contraloría General de la República, y otras instituciones, así como en el Distrito Especial de Bogotá y «en aquellas capitales departamentales que el Departamento Nacional de Planeación seleccione mediante resolución en razón de su tamaño o del valor de los proyectos» son revisados por las Direcciones Técnicas del DNP.

Si en la etapa de revisión se confirma la viabilidad del proyecto, entonces éste pasa a formar parte del BPIN y podrá ser incluido en el Plan Operativo de Inversiones. El BPIN es el Banco de Proyectos de Colombia donde se registran aquellos proyectos considerados viables, técnica, financiera, económica, social, institucional y ambientalmente.

El sistema en Colombia cuenta con Manuales, tanto de procedimientos como metodológicos ${ }^{18}$. Aparte de un Manual Metodológico General, para la Identificación, Preparación y Evaluación de Proyectos, en el caso específico de transporte hay

\footnotetext{
18 Estos se pueden encontrar en:

http://www.dnp.gov.co/PortalWeb/Políticas de Estado/BancodeProgramasyProyectosdeInversión Nal/ComponenteMetodológico.aspx.
} 
dos guías específicas. La Guía N. ${ }^{0} 5$ es para los Proyectos de Construcción, Mejoramiento y Rehabilitación de Infraestructura Vial y la Guía N. 7 es sobre el Modelo HDM para Proyectos de Construcción y Mejoramiento de Carreteras,

Las evaluaciones en Colombia utilizan precios sociales (denominados Razón Precio Cuenta) ${ }^{19}$. Estas razones se utilizan para transformar precios privados en precios sociales. Aparte de la razón para distintos costes de mano de obra y divisas, en el caso específico de transporte, se calculan razones de cuenta para el Transporte en general, Transporte de media distancia con dos ejes, Transporte de larga distancia con dos ejes, Transporte de larga distancia con tres ejes, Transporte de larga distancia con tres ejes y con remolque de dos ejes. Sin embargo, estos últimos parámetros se refieren a la producción de servicios de transporte y no hay un cálculo explícito del valor del tiempo, parámetro clave en el caso de la evaluación social de proyectos de transporte. Otro problema con los precios sociales (o razón precio cuenta) es que están bastante desactualizadas, ya que datan del año 1990.

En Colombia también se ha desarrollado una Metodología de Seguimiento de los Proyectos que busca «revisar la evaluación ex-ante que permitió el desarrollo de proyecto, analizar las condiciones que permitieron la selección e implementación del mismo, verificar generación de empleo, la promoción en el consumo de bienes y servicios, la adecuada asignación de recursos del Presupuesto de Inversión Pública, objetivos que se buscaban al poner en marcha el proyecto» ${ }^{20}$. También se ha desarrollado una metodología de evaluación ex-post, que busca evaluar la efectividad y eficacia de los proyectos. Estas dos metodologías se asemejan a los que en Chile se denominan evaluación ex-post simplificada y evaluación ex-post en profundidad.

\subsection{SNIP en México}

El Sistema de Inversión Pública (SNIP) en México, denominado Sistema de Inversiones, tiene por objetivos declarados lograr una asignación eficiente de los recursos públicos, construir una herramienta para la toma de decisiones, constituir una cartera de proyecto de inversión que contribuya al crecimiento y desarrollo económico del país. Tiene como entidad rectora a la Secretaria de Hacienda y Crédito Público (SHCP), a través de la Unidad de Inversiones (UI).

La Ley Federal de Presupuesto y Responsabilidad Hacendaria, promulgada el año 2007, establece como uno de los requisitos para que un proyecto o programa de inversión reciba financiamiento del presupuesto federal que se presente a la SHCP un análisis costo beneficio ${ }^{21}$. Existen distintos niveles de profundidad del análisis

\footnotetext{
19 http://www.dnp.gov.co/PortalWeb/Portals/O/archivos/documentos/DIFP/Bpin/Estimación_de_ precios_de_cuenta_para_Colombia.pdf.

${ }^{20}$ DNP (2006), página 10.

${ }^{21}$ Un análisis coste-beneficio no se exige cuando el proyecto o programa se justifica en una atención urgente por desastres naturales.
} 
requerido, según el tipo y monto del proyecto. Para el caso de infraestructura, como la de transportes, los tipos de análisis requeridos son los que se establecen en el siguiente cuadro. El mismo requisito aplica para los proyectos de concesión a privados (PPP) cuando éstos requieren de financiamiento o subsidios públicos.

\section{CUADRO 3}

TIPOS DE ANÁLISIS COSTE BENEFICIO PARA PROYECTOS DE INFRAESTRUCTURA, MÉXICO

\begin{tabular}{|l|c|c|c|}
\hline \multicolumn{1}{|c|}{ Tipo } & $\begin{array}{c}\text { Informe de } \\
\text { Justificación } \\
\text { Económica }\end{array}$ & $\begin{array}{c}\text { Análisis Coste } \\
\text { Beneficio simplificado } \\
\text { (etapa pre-factibilidad) }\end{array}$ & $\begin{array}{c}\text { Análisis Coste } \\
\text { Beneficio } \\
\text { (etapa factibilidad) }\end{array}$ \\
\hline $\begin{array}{l}\text { Inversión } \\
\text { Manutención }\end{array}$ & $\begin{array}{c}<5 \text { US\$ millones } \\
<15 \text { US\$ millones }\end{array}$ & $\begin{array}{c}<50 \text { US\$ millones } \\
<50 \text { US\$ millones }\end{array}$ & $\begin{array}{c}>50 \text { US\$ millones } \\
>50 \text { US\$ millones }\end{array}$ \\
\hline
\end{tabular}

FUENTE: Basado en RAMÍREZ (2010) y «Lineamientos para la elaboración y presentación de los análisis coste-beneficio de los programas y proyectos de inversión» de la Secretaría de Hacienda y Crédito Público (publicado en el Diario Oficial el 18 de marzo del 2008).

La diferencia entre un análisis de coste-beneficio simplificado y no simplificado es el nivel de profundidad con que se realiza el análisis y la etapa del desarrollo del proyecto. Pero en ambos casos, el análisis debe contener, entre otros elementos, un diagnóstico de la situación sin proyecto y la problemática que busca resolver el proyecto, las otras alternativas disponibles para resolver el problema en cuestión y por qué no fueron seleccionadas, el Valor Presente Neto (NPV) del proyecto considerando una tasa de descuento (real) del 12 por 100 y la TIR. En el caso de la infraestructura, el proponente también debe presentar un análisis de viabilidad técnica, legal y económica.

Cuando un proyecto o programa sufre una modificación en su alcance, medido como un aumento en el monto de inversión, el proponente deberá actualizar el análisis costo beneficio. Por ejemplo, para proyectos grandes (inversión superior a los 10.000 millones de pesos) el análisis deberá actualizarse si el monto de inversión varía en 10 por 100 o más. Para aquellos entre mil millones y 10.000 millones, la actualización se debe hacer si la inversión sube un 15 por 100. Para los proyectos menores a mil millones, cuando la inversión sube en un 25 por 100 se debe actualizar el análisis.

La institución pública que propone el proyecto o programa debe presentar los antecedentes, incluyendo el análisis costo beneficio, a la SHCP. La SHCP resolverá dentro de veinte días hábiles si aprueba el análisis (en cuyo caso emite una clave y registra la iniciativa en la Cartera que se describe más adelante), solicita mayores antecedentes o rechaza la iniciativa (SHCP, 2008). Es interesante señalar que la SHCP puede solicitar que el análisis sea revisado por un experto independiente. Para los proyectos de más de 500 millones de pesos (50 millones de dólares) del sector 
de energía, agua y transporte, tal revisión por un experto independiente es obligatoria. Este fue el caso, por ejemplo, del proyecto de la línea 12 del Metro en la capital Mexicana (Spectron Desarrollo, 2009).

Si la UI confirma que dicha iniciativa es socialmente rentable (TIR igual o superior al 12 por 100) entonces el proyecto obtiene una clave e ingresa a la Cartera de Inversiones. Cabe destacar que sólo los programas y proyectos de inversión registrados en la cartera se podrán incluir en el proyecto de Presupuesto de Egresos. El Proceso de Registro está sistematizado vía electrónica y no requiere de documentación en papel (Ramírez, 2010). Este sistema recibe el nombre de «Módulo Integral de Programas y Proyectos de Inversión» (MIPPI), en donde sus funciones corresponden a gestionar solicitudes por parte de las dependencias y entidades, recibir el análisis costo y beneficio de los proyectos además de documentación de soporte y realizar seguimiento de la ejecución y de la rentabilidad del proyecto.

Existe un manual metodológico general para la preparación y evaluación de proyectos. Pero además, existen manuales específicos sectoriales (Ramírez, 2010). En el caso de transportes, hay manuales específicos para proyectos de inversión en carreteras, caminos rurales, ferrocarriles, y proyectos de transporte masivos como BRT (Bus Rapid Transit, trenes interurbanos y ferrocarriles livianos).

En el caso de proyectos transportes, se considera como costos las inversiones, gastos de mantención, gastos operativos, reinversiones, y costos de disrupción durante el período de construcción. Como beneficios se consideran los ahorros de tiempo de viaje, ahorros en gastos de mantención de vehículos, ahorros en operación y mantención, ahorros en costos de emisión y los valores residuales de los distintos bienes. Cabe destacar que la reducción de externalidades, cambios en la calidad de servicio y seguridad, y los posibles beneficios indirectos del desarrollo local relacionados con obras de inversión en transportes, no son considerados en la evaluación monetaria de los costes y beneficios. Esto se hace para centrar los cálculos de costes y beneficios en valores objetivos donde existe un cierto consenso sobre su valoración.

Los lineamientos para el análisis de coste-beneficio también recomiendan el uso de precios sociales, o en su defecto, precios privados netos de impuestos y subsidios. Sin embargo, no se pudo obtener información sobre el uso generalizado de precios sociales en el caso de proyectos de transportes.

Si bien el sistema considera la evaluación ex-post como un elemento integral del sistema de inversiones, no existen antecedentes públicamente disponibles como para evaluar el estado del arte en esta materia en el caso de México.

Por último, se debe señalar que lo descrito en esta sección es aplicable a las inversiones financiadas con recursos del gobierno Federal. No está claro si los gobiernos estatales y locales tienen sistemas de inversión como el descrito aquí, y si realizan o no análisis coste beneficio de los proyectos que ellos financian. Tampoco fue posible estimar qué proporción de las inversiones globales de México pasan por el SNIP Federal. 


\subsection{SNIP en Perú}

La Dirección General de Programación Multianual del Sector Público (DGPM) del Ministerio de Economía y Finanzas (MEF) es un órgano del Vice Ministerio de Economía que se encarga de la rectoría del Sistema Nacional de Inversión Pública (SNIP) cuyo objetivo es optimizar el uso de los recursos públicos destinados a inversión. El SNIP es un sistema administrativo y se compone de actores, reglas y procesos que actuando de manera interrelacionada persiguen dicho objetivo. Esta institución, se encarga de dictar las normas que regulan las etapas y fases del ciclo de vida de un proyecto. Así como también, las atribuciones de los distintos organismos dentro del SNIP.

El SNIP fue creado a partir de la promulgación de la Ley N. ${ }^{\circ} 27.293$. el 28 de junio de 2000. Antes de ello, la Oficina de Inversiones, del Ministerio de Economía y Finanzas, solamente evaluaba los proyectos financiados con endeudamiento externo (65 por 100 de la inversión del Gobierno Central). Ahora, sin embargo, su ámbito de actividades se amplía al conjunto de la inversión pública del gobierno, incluyendo los proyectos de las empresas públicas que no pertenezcan al sector financiero. Sin embargo están exceptuados de la norma los gobiernos municipales y sus empresas.

Entre los objetivos del SNIP, figura la de propiciar la aplicación del ciclo del proyecto de inversión pública desde el nivel de perfil, pasando por su estado de prefactibilidad, factibilidad, ejecución y evaluación ex-post. En términos del proceso, la elaboración del perfil de evaluación es obligatoria. Las evaluaciones de prefactibilidad y factibilidad pueden no ser requeridas dependiendo de las características del proyecto de inversión pública.

Cabe destacar la existencia de manuales que guían la creación de proyectos acordes al tamaño de la inversión. En particular, existe el Manual Metodológico General de Identificación, Formulación y Evaluación de Proyectos de Inversión Pública Grandes y Medianos, así como también, el Manual Metodológico General de Identificación, Formulación y Evaluación de Proyectos de Inversión Pública Menores. Junto a esto se han establecido manuales a nivel sectorial, para proyectos ambientales, educación, vialidad, servicios públicos, entre otros ${ }^{22}$.

Los proyectos del sector público constan de tres fases (Artículo 6). La primera fase se refiere a la preinversión del proyecto, en la cual se elaboran los estudios de prefactibilidad y factibilidad del proyecto. En esta fase, el SNIP, opera a través del Banco de Proyectos (Artículo 7), entidad que contiene el registro de todos los Proyectos de Inversión Pública (PIP), es decir, contiene el inventario de todos los PIP que se encuentran en la fase de pre-inversión, desde la aprobación de los estudios a nivel de perfil.

${ }^{22}$ Los Manuales Metodológicos de Perú se pueden encontrar en la página web: www.mef.gob. pe/DGPM/instrumentos.php. 
La segunda fase corresponde a la fase de inversión del proyecto, que establece la confección de un expediente que detalle de forma técnica la ejecución del proyecto. En esta fase opera el Sistema Operativo de Seguimiento y Monitoreo. La última fase corresponde a la fase de postinversión, aquí se establecen los procedimientos de control y evaluación ex-post.

Se identifica también la existencia de precios sociales incorporados en el proceso de inversión. Para el año 2009, algunos valores son los siguientes: tasa social de descuento (TSD) de 11 por 100, tasa social de descuento nominal de un 14 por 100 (nominal, pues es corregida por inflación), factor de ajuste para el valor social de las divisas de un 1,08 y valor social del tiempo para propósito laboral, particularmente del área urbana de 1,80 dólares a la hora ${ }^{23}$.

Existe un sistema de seguimiento, el cual aún debe profundizarse. Sin embargo es posible señalar con respecto a la evaluación ex-post de los programas y proyectos viables, que esta puede ser realizada por algún órgano que no necesariamente corresponde a la Unidad de Ejecución al que pertenece dicha inversión, sin embargo debe pertenecer al Sector, Gobierno Regional o Local, en donde haya finalizado la ejecución. La evaluación se realiza sobre una muestra representativa del total de los PIP. Para completar esta etapa se requiere la aprobación de la Oficina de Programación e Inversiones encargada y de la DGPM y será esta última quien determine las condiciones para evaluar.

\subsection{SNIP en Argentina}

El Sistema de Inversión Pública en el caso de Argentina se creó por la Ley N. ${ }^{\circ}$ 24.354, promulgada el 22 de agosto de 1994, con un apoyo decidido por parte de las autoridades de la época. Sin embargo, el sistema ha debido sortear diferentes situaciones tanto de tipo económicas como institucionales que han implicado una implementación parcial. Su principal objetivo es dar eficacia, eficiencia y efectividad a la asignación de recursos destinados a la inversión. Más específicamente el sistema pretende aumentar la productividad de la inversión, estructurando los procesos de creación, evaluación y selección de los mejores proyectos, registrándolos en el Banco de Proyectos de Inversión (BAPIN) creado para ello, para finalmente ser integrados en el Plan de Inversión Pública que aprueba el Parlamento Nacional de Argentina.

La Dirección Nacional de Inversión Pública (DNIP) del Ministerio de Economía y Obras y Servicios Públicos, es el principal encargado del SNIP en Argentina, pues es el responsable de elaborar estrategias de inversión pública de corto y mediano plazo, que sean coherentes con el crecimiento económico y social del país. Dicho organismo se hizo responsable por el SNIP de este país gracias al Decreto Parlamentario del Poder Ejecutivo Nacional N. ${ }^{0}$ 720/95, con fecha 22 de mayo de 1995.

\footnotetext{
${ }^{23}$ Para más información ver: www.mef.gob.pe/DGPM/docs/anexos/AnexoSNIP09v10.pdf.
} 
Otros organismos encargados, que apoyan la gestión de la DNIP son los siguientes los gobiernos provinciales, la autoridad ambiental cuando sea relevante y la Secretaría de Programación Económica.

El Sistema de Información existente en la DNIP, que se denomina Banco de Proyectos de Inversión Pública (BAPIN), está en proceso de reestructuración. Desde el punto de vista de la arquitectura computacional, el BAPIN está estructurado en forma descentralizada, constituyendo una red inter-institucional donde las diferentes jurisdicciones y entes pueden consignar en sus propias bases de datos (bancos de primera instancia) la información relativa a proyectos que caen bajo su responsabilidad directa. Esta información se globaliza en las bases de datos de la DNIP (banco de segunda instancia) durante los períodos de registro establecidos.

Con respecto a los precios sociales para la evaluación de los proyectos en Argentina se utiliza la tasa de descuento social del 12 por 100, como lo indica la Resolución N. ${ }^{\circ}$ 110/96 de la Secretaría de Programación Económica. Sin embargo, el artículo que se refería a éstos (Artículo 2) fue derogado por la Resolución N.$^{\circ}$ 100/97 por lo que no se cuenta con datos actualizados a la fecha con respecto a los precios de cuenta, que si bien se han hecho esfuerzos por establecer y estimar algunos de éstos, no ha finalizado con éxito pues no se han llegado a acuerdos tanto metodológicos como a magnitudes cuantitativas. Entonces, el enfoque utilizado actualmente es una aproximación a estos precios sociales, ocupando los precios de mercado netos del Impuesto al Valor Agregado (21 por 100). Sin embargo, es necesario mencionar que en casos particulares ( 1 por 100 de los proyectos evaluados y megaproyectos), se hace una estimación más cercana de estos precios sociales, pero adaptados para cada proyecto.

Cabe destacar la existencia de un manual metodológico para la preparación y evaluación de proyectos, denominada Guía General para Formulación y Evalua ción de Proyectos de Inversión Pública Nacional, dentro del cual se considera la evaluación ex-post de los proyectos ${ }^{24}$.

\subsection{SNIP en Brasil}

Para el caso de Brasil, el Sistema de Inversión Pública, respaldado por la Ley N. ${ }^{\mathrm{o}}$ 10.180 , tiene como principales objetivos formular, gestionar y evaluar estrategias de crecimiento social y económico a nivel país, así como también a nivel sectorial y regional, consistente con la planificación adecuada del presupuesto federal.

Dentro de los organismos encargados del Sistema de Planificación y Presupuesto Federal, destacan los siguientes ${ }^{25}$ :

\footnotetext{
${ }^{24}$ ORTEGÓN y PACHECO (2005).

25 ORTEGÓN y PACHECO (2005), página 38.
} 
- Ministerio de Planificación.

- Órganos sectoriales: Unidades de planificación y presupuesto de los ministerios, de la Abogacía gerencial de la Unión, de la Vice presidencia y de la casa Civil.

- Órganos específicos: Todos aquellos relacionados con las actividades de planificación y presupuesto.

Cabe destacar la existencia del Manual de Elaboración de Programas, perteneciente al Ministerio de Planificación, Presupuesto y Gestión, Secretaría de Planificación e Inversiones Estratégicas, el cual da los lineamientos para presentar y evaluar los proyectos de inversión. La evaluación del proceso es tarea de las UMA o Unidades de Monitoreo y Evaluación, avalado por el artículo 17 de la Ley N. ${ }^{\circ}$ 11.653.

El Ministerio de Planificación, los gerentes y gestores sectoriales, asegurar que los órganos participantes sean responsables de los siguientes conceptos:

- Eficacia y efectividad físico-financiero de los programas, para asignar correctamente los recursos públicos, la política de gastos y la coordinación de acciones gubernamentales.

- Que los programas mantengan rutinas de seguimientos, así como también de evaluación.

- Asesorar y evaluar la ejecución financiera, sin ir en desmedro de las competencias de los otros órganos.

Cabe agregar que la evaluación es hecha en tres etapas: Primero se encuentra la Evaluación del Programa, hecha por el gerente del proyecto el cual mide resultados y su implementación, luego está la evaluación sectorial (realizada por el Ministerio sectorial correspondiente) en donde se gestiona y ve la integración con el programa de la etapa anterior para finalmente terminar con la evaluación del Ministerio de Planificación, quien fiscaliza la coherencia del proyecto con el escenario macroeconómico y nuevamente gestiona la evaluación.

\section{Rol de las instituciones multilaterales}

Como se pudo observar de la sección anterior, con la posible excepción de Colombia, no todos los países tienen SNIP desarrollados que garanticen una correcta evaluación de los proyectos, aunque existen elementos que permiten el desarrollo de estos sistemas a futuro.

Sin embargo, es posible que en estos países las deficiencias de sus sistemas de inversión sean menos preocupantes toda vez que una parte importante de sus inversiones, y en particular las de infraestructura, son financiadas por organismos multi- 
laterales, como el BID o Banco Mundial ${ }^{26}$. Por ejemplo, como se señala más arriba, el 65 por 100 de la inversión del gobierno central del Perú es financiada con endeudamiento externo y probablemente una fracción mayoritaria de ésta proviene de organismos multilaterales.

El motivo para la afirmación del párrafo anterior es que los organismos multilaterales exigen una evaluación social de todos los proyectos, particularmente de infraestructura, que financian ${ }^{27}$. Además, cada organismo tiene manuales y procedimientos para realizar dichas evaluaciones. Por último, como la evaluación se realiza en conjunto con el país, generalmente existe algún grado de separación entre el proponente del proyecto y el evaluador.

Sin embargo, existen dudas respecto a la efectividad de estas evaluaciones. Algunos practicantes señalan que en el mejor de los casos sirven para modificar un proyecto no rentable socialmente pero que un gobierno quiere ejecutar y en el peor una barrera burocrática que se debe sortear para aprobar la financiación de un proyecto que de antemano se decidió ejecutar. De hecho, en el Banco Mundial se realizó recientemente una evaluación del uso del análisis coste-beneficio en los proyectos del Banco por parte del Grupo Evaluador Independiente (IEG) de esa institución ${ }^{28}$.

El informe (IEG, 2010) señala que el uso de análisis coste-beneficio de los proyectos financiados por el Banco ha decaído durante la última década, desde el 70 por 100 al 25 por 100 entre 1970 y 2008. Además, el informe señala que el análisis coste-beneficio se hace después que se ha tomado la decisión de realizar un proyecto, por lo que no tiene mucho impacto en la toma de decisiones.

A pesar de lo anterior, el informe también revela que el sector donde más se usa el análisis costo beneficio en el Banco Mundial es el de Transportes. El 58 por 100 de los proyectos de transporte (162) financiados entre el año 1970 y 2008 tenían una tasa de retorno económica calculada, evidencia indirecta de que un análisis costo beneficio había sido realizado. De los 27 proyectos de transportes aprobados durante el año fiscal 2008, 21 tenían una tasa de retorno calculada ex-ante y ex-post, el porcentaje más alto entre los proyectos de los distintos sectores. Además, la calidad de las evaluaciones de los proyectos de inversión en transportes era por lo general alta. El IEG (2010) atribuye en parte este resultado al instrumento metodológico desarrollado para proyectos de transportes (Highway Development Maintenance Model -HDM-, y el Roads Economic Decision Model) que facilitan el análisis coste-beneficio e requieren necesariamente la comparación entre proyectos alternativos.

\footnotetext{
${ }^{26}$ Este no es el caso de Chile, donde por lo general no se recurre a estas instituciones para la financiación de inversiones.

${ }^{27}$ Por ejemplo, la política del Banco Mundial en torno a estos temas está establecida en el documento de Política Operacional 10.04 del año 1994 titulado Economic Evaluation of Investment Ope rations y establece que el Banco debe elegir los proyectos de inversión que maximicen el valor presente neto (VPN) entre las alternativas y no financiar un proyecto cuyo VPN sea negativo. Cuando los beneficios de un proyecto resultan difíciles de cuantificar, la política oficial del Banco Mundial, expuesta en el mismo documento antes mencionado, es que se realice un análisis de coste-efectividad de las alternativas (IEG, 2010).

${ }^{28}$ El IEG es un comité independiente que revisa las actividades del Banco Mundial.
} 
El IEG (2010) también señala que en el Banco Mundial puede haber conflictos de interés que podrían sesgar las evaluaciones. Quienes realizan estas evaluaciones generalmente son profesionales (o consultores contratados por ellos) que tienen también un interés en promover los proyectos y su financiamiento. De hecho, en el caso de proyectos de transportes, el IEG (2010) cita un estudio sobre proyectos de carreteras en China, que compara evaluaciones ex-ante con resultados ex-post, y que muestra que existe un sesgo optimista en la evaluación de estos proyectos en ese país. Más preocupante es el hecho que este sesgo parece ser mayor entre los proyectos financiados por el Banco Mundial (sesgo de 5,5 puntos en la tasa de retorno) en comparación con aquellos proyectos financiados por el Banco de Desarrollo de Asia (sesgo de 3 puntos en la tasa de retorno) o financiados con recursos domésticos (sesgo de 2,5 puntos en la tasa de retorno).

Por lo anterior, para evitar el posible conflicto de interés de los profesionales del Banco Mundial y garantizar la calidad y objetividad de los estudios de rentabilidad social, el informe del IEG sugiere encargar éstos a una agencia independiente del país que está solicitando el crédito cuando exista y funcione con efectividad (IEG, 2010; Box 2). Pero esto es volver al punto de inicio de este trabajo, ya que esto es sinónimo a tener un SNIP funcionando.

Por lo tanto, no está claro que el proceso de evaluación que cumplen los proyectos al ser estos financiados por entidades multilaterales cumpla con ser un filtro efectivo para una buena asignación de recursos y sustituyan los beneficios de un buen SNIP.

\section{Evaluación de los SNIP: ¿ayudan a mejorar la evaluación social?}

Pero, ¿los SNIP son efectivos? En otras palabras, ¿los sistemas y diseños institucionales descritos anteriormente sirven para mejorar la evaluación de los proyectos y optimizar la asignación de fondos públicos? Realizar esta evaluación no es simple, ya que no resulta sencillo medir el impacto productivo que han tenido estos sistemas en comparación con una situación sin SNIP. En esta sección se presentará la información disponible que permita realizar una evaluación, aunque sea parcial.

La evaluación de los SNIP se puede hacer en dos dimensiones. Por un lado, simplemente evaluar éstos desde una perspectiva procesal. En otras palabras, cuantificar si los proyectos de inversión en un país se evalúan o no y cuál es la calificación que obtienen los proyectos ejecutados en esta dimensión. Una segunda aproximación, más difícil, es intentar evaluar la calidad de las evaluaciones ex-ante realizadas. Ambas dimensiones son importantes para el propósito final de la evaluación social. Si los proyectos no se evalúan, o está evaluación no tiene relevancia para definir los proyectos que se ejecutan, entonces la evaluación social no sería un instrumento útil para la toma de decisiones. A su vez, si los proyectos se evalúan, pero estas evaluaciones son de mala calidad, entonces el proceso de evaluación tampoco cumple su propósito. A continuación se examina la información disponible sobre ambos aspectos. 
Con respecto al tema puramente procesal, existe información para el caso de Chile. Como ya se había mencionado más arriba, según Dipres (2007) entre un 60 por 100 y 68 por 100 la inversión pública anual materializada entre los años 2003 y 2006 pasó por el SNI. La diferencia son proyectos que por su naturaleza (inversión en capital humano, mantención o conservación de infraestructura existente, iniciativas de las fuerzas armadas) no requieren formalmente ser evaluados.

Por otro lado, según la misma fuente entre el 52 por 100 y el 59 por 100 de los proyectos evaluados obtienen un RATE favorable (RS). Tal vez tan importante como lo anterior, es que un RATE favorable parece ser una condición necesaria para la materialización de un proyecto de inversión. Según Dipres (2007), entre el 2003 y 2005 en promedio sólo un 11 por 100 de los proyectos financiados y ejecutados (cerca de 5.000 proyectos) no contaban con una recomendación favorable de parte de Mideplan. Esto se puede deber a la urgencia requerida en la ejecución del proyecto (por ejemplo, reponer una obra de infraestructura que sufrió daño por razones de fuerza mayor) ${ }^{29}$.

Se debe señalar que la normativa vigente indica que un proyecto debe contar con una evaluación, no que el resultado tenga que ser favorable (socialmente rentable) para que se pueda ejecutar, salvo aquellos financiados por el FNDR que sí requieren una evaluación positiva. Sin embargo, las cifras anteriores indicarían que en general los proyectos ejecutados son aquellos que tienen una evaluación social positiva.

Por lo tanto, en el caso de Chile se podría afirmar que se cumplen las condiciones procesales requeridas para que la evaluación social sea potencialmente un instrumento útil de toma de decisiones en el sector público. Según los practicantes, una de los beneficios de los esfuerzos realizados en este sentido, es que se ha instalado una «cultura» de evaluación en el sector público. En el sentido de que sus profesionales ya están familiarizados con la importancia de evaluar los proyectos y con los conceptos de rentabilidad social de las inversiones.

En cuanto a la calidad de las evaluaciones, existen algunos antecedentes. En primer lugar, el proceso de supervisión que realiza anualmente Mideplan arroja que un 15 por 100 de los proyectos con RATE favorable en realidad no cumplían con las condiciones técnicas para obtener dicha calificación (Dipres, 2007). Sin embargo, idealmente este proceso de supervisión debería realizarlo un organismo externo y no internamente por Mideplan.

En segundo lugar, como ya se ha señalado anteriormente, Mideplan debe realizar una evaluación ex-post simplificada de un conjunto representativo de proyectos financiados por el FNDR. En el año 2009 se revisaron 259 proyectos, la mayoría de

\footnotetext{
${ }^{29}$ Aunque no está reconocida formalmente en el SNI, existe un RATE adicional denominado 'PP' (Prioridad Presidencial) que a veces se utiliza informalmente para evaluar y aprobar muy rápidamente un proyecto que el Presidente de la República considera prioritario. Durante el último gobierno (20062010) no se evaluó ni ejecutó ningún proyecto mediante esta modalidad.
} 
los cuales eran pequeños con un presupuesto menor a 600.000 dólares $)^{30}$. En general, las estimaciones de costes ex-ante resultaron ser acertadas. En la mitad de los casos la inversión efectiva ex-post resultó ser menor a la estimada originalmente y en un número similar de proyectos la diferencia no era mayor a un 20 por 100 del presupuesto original. Sin embargo, el mismo estudio concluye que los plazos de ejecución son superiores a los estimados ex-ante.

Las evaluaciones ex-post simplificadas no permiten evaluar la calidad de las proyecciones de demanda o beneficios de los proyectos. Tampoco es seguro que los proyectos del FNDR sean representativos de la inversión pública sectorial, que en términos del volumen de recursos es mucho más importante que la inversión asociada al FNDR ${ }^{31}$. Es posible que los proyectos financiados con el FNDR sean de menor envergadura y más simples de evaluar que los sectoriales, por lo que los resultados relativamente favorables de Mideplan (2009b) no pueda extenderse al resto de las evaluaciones.

Mideplan también ha realizado evaluaciones ex-post en profundidad. El cuadro 4 presenta los resultados de los estudios ex-post disponibles para siete proyectos de transportes ${ }^{32}$. La mayoría de estos proyectos se ejecutaron durante los años noventa o comienzos de la década pasada.

En el cuadro 4 se puede apreciar que salvo en el caso de un proyecto, la inversión efectiva de los proyectos está dentro de un rango razonable (menos del 20 por 100) con respecto a lo estimado originalmente. Incluso, en el caso de Avenida Las Golondrinas, donde la inversión resultó ser un 60 por 100 superior a lo estimada exante, la rentabilidad ex-post del proyecto (24 por 100) fue mayor a lo evaluado inicialmente $(18,6$ por 100$)$. Esto se debe a que la subestimación de los beneficios más que compensó el mayor costo de inversión.

\footnotetext{
${ }^{30}$ Desafortunadamente, MIDEPLAN (2009b) no entrega cifras por sector, por lo que no es posible analizar sólo los proyectos del sector transportes.

${ }^{31}$ Como ya se señaló más arriba, la inversión del FNDR representa cerca del 15 por 100 de la inversión pública.

${ }^{32}$ Los informes se pueden encontrar en http://sni.mideplan.cl
} 


\section{CUADRO 4}

\section{COMPARACIÓN EVALUACIÓN EX-ANTE Y EX-POST DE PROYECTOS DEL SECTOR TRANSPORTE}

\begin{tabular}{|c|c|c|c|}
\hline Proyecto & Ex-Ante & Ex-Post & Diferencia \% \\
\hline $\begin{array}{l}\text { Mejoramiento Ruta M-40, VII Región } \\
\text { (inicio 2000) } \\
\text { Coste Inversión (MM\$ 31/12/1995) } \\
\text { Flujo año } 2005 \text { (TMDA) } \\
\text { TIR }\end{array}$ & $\begin{array}{l}1.108,01 \\
1.065 \\
27,5 \%\end{array}$ & $\begin{array}{l}154,5 \\
494 \\
14,3 \%\end{array}$ & $\begin{array}{r}4,2 \% \\
-53,6 \% \\
-48,0 \%\end{array}$ \\
\hline $\begin{array}{l}\text { Construcción Acceso y Costanera Norte } \\
\text { Sector Hornitos, II región (inicio 2002) } \\
\text { Coste Inversión (MM\$ 31/12/2001) } \\
\text { Flujo año } 2005 \text { (TMDA) } \\
\text { TIR }\end{array}$ & $\begin{array}{l}779,3 \\
296,1 \\
373 \\
18,5 \%\end{array}$ & $\begin{array}{l}674,2 \\
296,1 \\
204 \\
12,3 \%\end{array}$ & $\begin{array}{r}-13,5 \% \\
0,0 \% \\
-45,3 \% \\
-33,5 \%\end{array}$ \\
\hline $\begin{array}{l}\text { Habilitación Acceso a Iquique, } \\
\text { I región (inicio 1999) } \\
\text { Coste Inversión (MM\$31/12/2000) } \\
\text { Flujo año } 2004 \text { (flujo/hr ambos sentidos) } \\
\text { TIR }\end{array}$ & $\begin{array}{l}5.062 \\
1.155 \\
32,0 \%\end{array}$ & $\begin{array}{l}5.732 \\
1.788 \\
74 \%\end{array}$ & $\begin{array}{r}13,2 \% \\
54,8 \% \\
131,2 \%\end{array}$ \\
\hline $\begin{array}{l}\text { Mejoramiento Avenida Las Golondrinas, } \\
\text { Talcahuano, VIII región (inicio 2002) } \\
\text { Coste Inversión (MM\$ 31/12/2000) } \\
\text { TIR }\end{array}$ & $\begin{array}{c}7.847 \\
18,6 \%\end{array}$ & $\begin{array}{l}12.555 \\
24,0 \%\end{array}$ & $\begin{array}{l}60,0 \% \\
29,0 \%\end{array}$ \\
\hline $\begin{array}{l}\text { Mejoramiento Ruta S-11-R, Etapa III, } \\
\text { IX región (inicio 1995) } \\
\text { Coste Inversión (MM\$ 7/1995) } \\
\text { VAN (MM\$ 7/1995) } \\
\text { TIR }\end{array}$ & $\begin{array}{r}2.322,7 \\
696,5 \\
19,23 \%\end{array}$ & $\begin{array}{l}2.348,1 \\
1.704\end{array}$ & $\begin{array}{r}1,1 \% \\
144,7 \%\end{array}$ \\
\hline $\begin{array}{l}\text { Mejoramiento Ruta D-485, IV región } \\
\text { (inicio 1995) } \\
\text { Coste Inversión (MM\$ 31/12/1993) } \\
\text { Flujo año } 2000 \text { (TMDA) } \\
\text { TIR }\end{array}$ & $\begin{array}{l}1.274,1 \\
1.115 \\
14,5 \%\end{array}$ & $\begin{array}{l}1.438,0 \\
1.862 \\
13,0 \%\end{array}$ & $\begin{array}{r}12,9 \% \\
70,0 \% \\
-10,3 \%\end{array}$ \\
\hline $\begin{array}{l}\text { Mejoramiento pasada por Valdivia, } \\
\text { eje Picarte, X región } \\
\text { TIR }\end{array}$ & $22,4 \%$ & $17,1 \%{ }^{\mathrm{d}}$ & $-23,4 \%$ \\
\hline
\end{tabular}

NOTAS: ${ }^{a}$ El primer número corresponde a la Etapa I del proyectos y el segundo el de la Etapa II del proyecto. Para los flujos y TIR, los datos corresponden a la Etapa II del proyecto. ${ }^{\mathrm{b}}$ Los datos mostrados incorporan la interconexión vial que se decidió construir además del proyecto original. Además, las cifras son de la última re-evaluación (año 1999) no la evaluación original (1993). ${ }^{\mathrm{c}}$ Considera la suma del flujo del Sector 1 y 2 del proyecto. ${ }^{\mathrm{d}}$ No incluye el proyecto de aguas lluvia.

FUENTE: MIDEPLAN. 
La volatilidad de las estimaciones de demanda para aquellos proyectos donde esta información estaba disponible, es sorprendentemente alta. En algunos casos, los flujos puntuales se subestimaron en un 50 por 100 a un 70 por 100 , mientras que en otros se sobrestimó en cerca de un 50 por 100. Este hecho probablemente esté asociado a las dificultades propias de estimar una demanda, en comparación con los costos de inversión de un proyecto de transportes. Los estudios también señalan que en general en las evaluaciones ex-ante se sobrevaloran las tasas de ocupación, pero se subvaloran las tasas de crecimiento de la demanda y las velocidades efectivas. Los plazos de ejecución también han sido generalmente optimistas.

En cuatro de los siete proyectos con evaluación ex-post, la rentabilidad social efectiva del proyecto es menor a la estimada originalmente. Pero se debe señalar que en todos los casos los proyectos seguían siendo socialmente rentables a pesar de la menor rentabilidad efectiva. Sin embargo, no está claro si hay un sesgo de selección de los proyectos con evaluaciones ex-post, o si estos proyectos son representativos de la cartera completa de proyectos ejecutados en el sector transportes.

En definitiva, para el caso de Chile, la evidencia disponible indicaría que las evaluaciones ex-ante logran un nivel aceptable de precisión. Esto, junto con el cumplimiento de los aspectos netamente procesales del sistema de evaluación tendería a apoya la hipótesis de que el SNI ha sido efectivo para garantizar una alta calidad de la evaluación social ex-ante de los proyectos y garantizar, en consecuencia, una buena asignación de recursos públicos. Sin embargo, la poca información de estudios ex-post, tanto los simplificados como en profundidad, no permite ser demasiado enfáticos respecto a esta conclusión. Sin perjuicio de lo anterior, Contreras, Cartes y Pacheco (2010) afirman que «A nuestro juicio existe un amplio consenso en que el sistema ha sido (con todas la deficiencias que aún pueda tener) un aporte a la mejora en la asignación de recursos». ${ }^{33}$

Para el resto de los países de la región, exist escasa información para poder evaluar la operación de sus sistemas de inversión. Una excepción es el estudio de EMBARQ (2009) donde se realiza una evaluación ex-post del Sistema de Transporte Masivo de Bogotá, más conocido como TransMilenio ${ }^{34}$.

Aparte de realizar una evaluación ex-post de la Fase I y II de esta reforma -implementada entre los años 2000 y 2008 y consistente en 84 kilómetros de corredores exclusivos- en dicho trabajo se comparan los resultados con los obtenidos en las evaluaciones $e x$-ante realizadas tanto por el Gobierno de Colombia en el año 2000 (DNP, 2000) como por el Banco Mundial (World Bank, 2003 y 2004), institución que financió parte de la inversión del proyecto.

33 Página 32. Estos autores también presentan una lista de problemas y aspectos por mejorar del SNIP de Chile. Entre ellos, el posible conflicto de intereses dentro de Mideplan al ser un organismo evaluador pero a su vez un organismo que define ciertos gastos sociales. Por otro lado, estos autores advierten de la presión política que enfrentan los analistas, particularmente en regiones, por dar una recomendación favorable a ciertos proyectos, independientemente de su mérito técnico.

${ }^{34}$ Este proyecto es un sistema integrado de transporte de buses de alta capacidad, con infraestructura dedicada (corredores exclusivos para transporte público, estaciones con acceso a nivel y donde los pasajeros pagan antes de abordar los buses, gestión de flota moderna), pago electrónico y sistema centralizado de recaudación y pagos. Es un ejemplo emblemático de los llamados BRT ('Bus Rapid Transit'), sistemas que han proliferado en el mundo durante la última década. 
CUADRO 5

AVANCE FÍSICO Y FINANCIERO PLAN DE DE IMPLANTACIÓN SEGÚN CONPES 3039 PERÍODO 2000-2008

\begin{tabular}{|l|c|c|c|}
\hline & Planeado & Realizado & Avance \\
\hline Kilómetros corredor troncal & 172 & 84 & $49 \%$ \\
\hline Demanda Pasajeros/día laboral & 3.319 .385 & 1.600 .000 & $48 \%$ \\
\hline Pasajero día por kilómetro troncal & 19.254 & 19.047 & \multirow{2}{*}{$99 \%$} \\
\hline Inversión pública US millones 2000 & 719,5 & $1 ., 476,0$ & \multirow{2}{*}{$205 \%$} \\
\cline { 1 - 2 } Inversión pública miles millones 2008 & 2.199 .2 & $4.511,3$ & \\
\cline { 1 - 2 } Inversión pública US millones 2000/km & 4,17 & 17,57 & \multirow{2}{*}{$421 \%$} \\
\cline { 1 - 2 } Inversión pública miles millones 2008/km & 12,76 & 53,71 & \\
\hline
\end{tabular}

FUENTE: EMBARQ (2009), Tabla 4.3.

Esta comparación es interesante ya que revela que la evaluación del plan completo realizado por el Gobierno de Colombia en el año 2000 (DNP, 2000) fue demasiado optimista por el lado de los costos, pero la proyección de demanda fue bastante acertada. Los detalles se presentan en el Cuadro 5. Los 84 kilómetros construidos en la Fase I y II constituyen el 49\% del plan global evaluado en el año 2000, de 172 kilómetros. La demanda ex-post por kilómetro construido en estas dos fases fue casi idéntica a la demanda proyecta inicialmente (19.047 versus 19.254 por día kilómetro troncal). Sin embargo, la inversión por kilómetro fue casi 3 veces mayor a la proyectada inicialmente (17,57 US\$ millón versus 4,17 US\$ millón por kilómetro). Según EMBARQ (2009) esto se debió al «...resultado de múltiples requerimientos no previstos inicialmente sobre la estructura de los pavimentos, afectación al tráfico mixto, adquisición de predios, compensación de condiciones iniciales a propietarios y residentes, intersecciones a desnivel, capacidad de terminales y patios, requerimientos de reubicación de redes de servicios públicos, y necesidades de financiación (crédito de concesionarios o titularización de vigencias futuras)» ${ }^{35}$.

\footnotetext{
${ }^{35}$ EMBARQ (2009), págs. 64-65.
} 
Si se revisa la evaluación del Plan contenida en DNP (2000) con la información real del costo de la infraestructura, además de algunas otras modificaciones, los resultados son los que se presentan en el cuadro $6^{36}$. Se puede observar que la TIR disminuye de un 61,1 por 100 calculado originalmente a un 16,4 por 100 actualizado. Aún cuando ex-post el proyecto completo sigue siendo socialmente rentable (al estar por sobre la tasa de descuento social del 12 por 100 definido para Colombia) se evidencia una sobre estimación significativa de la rentabilidad ex-ante del proyecto debido, fundamentalmente, a una subestimación de los costos de inversión. Este resultado, junto con una evaluación ex-post social de las Fases I y II de la reforma, llevan a EMBARQ (2009) a afirmar que «Estos resultados sugieren una alta conveniencia del proyecto completo, condicionada en inversiones públicas en infraestructura del orden de 50 por 100 del valor de las Fases I y II, es decir, \$27 mil millones de 2008 por kilómetro (USD 13 millones por kilómetro)» ${ }^{37}$.

\section{CUADRO 6 \\ INDICADORES DE EVALUACIÓN SOCIO-ECONÓMICA PLAN CONPES 3093}

\begin{tabular}{|l|c|c|c|}
\hline & $\begin{array}{c}\text { Evaluación } \\
\text { revisada } \\
\mathbf{1 9 9 8 - 2 0 4 0}\end{array}$ & $\begin{array}{c}\text { Evaluación } \\
\text { original } \\
\mathbf{1 9 9 8 - 2 0 3 0}\end{array}$ & Diferencia \\
\hline $\begin{array}{c}\text { Valor Presente Neto 12\% } \\
\text { (miles de millones de pesos de 2008) }\end{array}$ & $\$ 2.225,45$ & $\$ 4.569,45$ & $48,7 \%$ \\
\hline $\begin{array}{l}\text { Valor Anual Equivalente 12\% } \\
\text { (miles de millones de pesos de 2008 }\end{array}$ & $\$ 269,11$ & $\$ 563,32$ & $47,7 \%$ \\
\hline Razón Beneficio Costo & 1,193 & 2,45 & $83,8 \%$ \\
\hline Tasa Interna de Retorno Social & $16,4 \%$ & $61,1 \%$ & $26,8 \%$ \\
\hline
\end{tabular}

FUENTE: Tabla 5.8 de EMBARQ (2009). Estos valores son sociales, en el sentido de que se utilizaron precios sociales para realizar los cálculos.

Los resultados comparativos con otros estudios se presentan en el Cuadro 7. Se puede observar que la rentabilidad social ex-post de la Fase I y II de TransMilenio calculada por EMBARQ (2009) es parecida a la calculada por el Banco Mundial en sus dos estudios, aunque estos estudios no son directamente comparables ya que la evaluación del Banco Mundial es para un subconjunto de las inversiones relacionadas con esta reforma.

\footnotetext{
${ }^{36}$ La modificación más significativa a la evaluación inicial fueron los valores del costo de la infraestructura, pero también se modificó el horizonte de evaluación, se incluyeron costos de reposición de infraestructuras y equipos, los costos de la entidad de gestión y control del sistema, los valores residuales de las obras y equipos, las pérdidas de tiempo de viaje durante la etapa de construcción, los beneficios de tiempos de viaje de acuerdo a una nueva modelación de flujos, incluyendo los efectos sobre el tráfico mixto y los beneficios por reducción de accidentes y contaminación.

${ }^{37}$ EMBARQ (2009), pág. 73.
} 
CUADRO 7

COMPARACIÓN SELECTIVA DE EVALUACIONES DEL SISTEMA TRANSMILENIO*

\begin{tabular}{|l|c|c|c|c|}
\hline \multicolumn{1}{|c|}{ Evaluación } & $\begin{array}{c}\text { Valor Presente } \\
\text { Neto (12\%) US\$ } \\
\text { Millones (año) }\end{array}$ & $\begin{array}{c}\text { Relación } \\
\text { Beneficio/ } \\
\text { Coste }\end{array}$ & $\begin{array}{c}\text { Tasa Interna de } \\
\text { Retorno Socio- } \\
\text { económico }\end{array}$ & $\begin{array}{c}\text { Alcance/ } \\
\text { Horizonte }\end{array}$ \\
\hline $\begin{array}{l}\text { Documento } \\
\text { CONPES 3093, } \\
\text { DNP (2000) }\end{array}$ & 1.495 (1998) & 2,45 & $61,1 \%$ & $\begin{array}{c}24 \text { troncales, } \\
384 \mathrm{~km}, 32 \text { años, } \\
\text { evaluación } \text { ex-ante }\end{array}$ \\
\hline World Bank (2003) & $122,3(2002)$ & 1,37 & $24,7 \%$ & $\begin{array}{c}10,3 \mathrm{~km}, \text { Avenida } \\
\text { Suba, } 10 \text { años, } \\
\text { evaluación } \text { ex-ante }\end{array}$ \\
\hline World Bank (2004) & $163,74(2003)$ & 1,45 & $21,4 \%$ & $\begin{array}{c}19,3 \mathrm{~km}, \text { NQS, } \\
10 \text { años, } \\
\text { evaluación } \text { ex-ante }\end{array}$ \\
\hline EMBARQ (2009) & $1.064,3$ (2008) & 2,50 & $24,2 \%$ & $\begin{array}{c}84 \text { km, Fases I y II, } \\
20 \text { años, } \\
\text { evaluación } \text { ex-post }\end{array}$ \\
\hline
\end{tabular}

NOTA: * EMBARQ (2009) presenta comparaciones con más estudios ex-post. En El Cuadro 6 sólo se han incluido los estudios ex-ante más la realizada ex-post en EMBARQ (2009).

FUENTE: EMBARQ (2009), Tabla 3.22.

\section{Consideraciones finales}

En este documento se ha intentado describir, a partir de la experiencia de Chile y otros países latinoamericanos, las medidas institucionales que se pueden tomar para mejorar la eficacia de las evaluaciones sociales de proyectos.

Entre los elementos se destacan la separación entre el ente proponente y el ente evaluador de los proyectos, una base normativa fuerte que incluya el desarrollo de metodologías y procedimientos, mecanismos de control de calidad y supervisión, y un compromiso permanente por la evaluación ex-post para retroalimentar el sistema.

No todos estos elementos están presentes en los SNIP de los países de la región. Incluso en el caso de Chile, cuyo sistema de inversión es el más desarrollado e institucionalizado, existen recomendaciones que podrían mejorar el sistema. Por ejemplo, delegar la supervisión de la calidad de las evaluaciones a un comité externo o una superintendencia. En este sentido el caso de México es interesante ya que el organismo evaluador cuento con la asesoría de un Centro Académico externo.

También existen amplios espacios para mejorar y fortalecer la retroalimentación desde las evaluaciones ex-post a la evaluación ex-ante de los proyectos. Esto no solamente en Chile, sino en el resto de la región. Si bien todos los sistemas reconocen la importancia de la evaluación ex-post en general hasta la fecha no existen sis- 
temas instalados para retroalimentar fácilmente las metodologías y parámetros de estas evaluaciones al análisis ex-ante.

Por otro lado, con la excepción de Chile, en la región también existe cierto atraso en el desarrollo de sistemas de determinación y actualización de los precios sociales. En el caso de Colombia estos precios están muy desactualizados y en caso de México son calculados en forma ad-hoc para cada proyecto, sin aprovechar las inherentes economías de ámbito que existe en este campo.

Finalmente se debe señalar que nunca será posible diseñar un sistema que blinde a las evaluaciones de todas las presiones políticas que puedan surgir. Tampoco para razonable que sea conveniente hacerlo en un contexto de democracias representativas. Sin embargo, la evidencia disponible, al menos para el caso de Chile, indica que el diseño institucional de los sistemas nacionales de inversión, sí puede contribuir a potenciar el uso de la evaluación social de proyectos y mejorar así la asignación de los recursos públicos.

\section{Referencias bibliográficas}

[1] ALDUNATE, E. (2010): «Retos de los Sistemas Nacionales de Inversión Pública de América Latina para el año 2021», presentación en el Encuentro Nacional «Balance del Sistema de Inversión Pública en el Perú a los 10 años de su creación y retos para el 2021», Lima, Perú, 1 y 2 de Julio, 2010.

[2] CONTRERAS, E.; Cartes, E., y Pacheco, J. F. (2010): «Los SNIP de América Latina y el Caribe: Historia, evolución y lecciones aprendidas», Documentos de Trabajo Serie Gestión N. ${ }^{\circ}$ 124, Instituto Latinoamericano y del Caribe de Planificación Económica y Social (ILPES), Área de proyectos y programación de Inversiones, CEPAL, julio.

[3] DIPRES (2007): Minuta Ejecutiva: Programa Sistema Nacional de Inversiones, elaborada por la Dirección de Presupuestos, Ministerio de Hacienda, Gobierno de Chile, junio.

[4] DNP (2000): Sistema de Servicio Público Urbano de Transporte Masivo de Pasajeros de Bogotá -Seguimiento -, Departamento Nacional de Planeación, Documento CONPES 3093, noviembre 15.

[5] DNP (2006): Manual de Procedimientos del Banco de Programas y Proyectos de Inver sión Nacional, BPIN, Dirección Nacional de Planeación, Grupo Asesor de la Gestión de Programas y Proyectos de Inversión Pública, Dirección de Inversión y Finanzas Públicas, Bogotá D.C., diciembre.

[6] EMBARQ (2009): «Evaluación Ex-Post Sistema de Transporte Masivo de Bogotá, Fase I y II», Centro de Transporte Sostenible del Instituto de Recursos Mundiales WRI, 10 G Street NE Suite 800, Washington, DC, 20002, EEUU.

[7] IEG (2010): «Cost-Benefit Analysis in World Bank projects», Report by the Independent Evaluation Group of The World Bank, Washington D.C., june.

[8] MIDEPLAN (2009a): Manual de Procedimientos, Sistema Nacional de Inversiones, Subsistema Análisis Técnico-Económico, Ministerio de Planificación, División Planificación, Estudios e Inversión. 
[9] MIDEPLAN (2009b): Evaluación Ex-Post Simplificada a Proyectos, Programas y Estudios Básicos Financiados con el FNDR: Proceso 2009, Ministerio de Planificación, División Planificación, Estudios e Inversión, octubre.

[10] ORTEGÓN, E., y Dorado, D. (2006): Los sistema nacionales de inversión pública en Barbados, Guyana, Jamaica y Trinidad y Tobago, Serie Manuales número 46, Instituto Latinoamericano y del Caribe de Planificación Económica y Social (ILPES), Área de proyectos y programación de Inversiones, CEPAL, enero.

[11] ORTEGÓN, E., y Pacheco, J.F. (2004): Los sistemas nacionales de inversión pública en Centroamérica: marco teórico y análisis comparativo multivariado, Serie Manuales número 34, Instituto Latinoamericano y del Caribe de Planificación Económica y Social (ILPES), Área de proyectos y programación de Inversiones, CEPAL, agosto.

[12] ORTEGÓN, E., y Pacheco, J.F. (2005): Los sistemas nacionales de inversión pública en Argentina, Brasil, México, Venezuela, y España como caso de referencia (cuadros comparativos), Serie Manuales número 40, Instituto Latinoamericano y del Caribe de Planificación Económica y Social (ILPES), Área de proyectos y programación de Inversiones, CEPAL, junio.

[13] RAMÍREZ, V. (2010): «The Practice of Cost-Benefit Analysis in the Transport Sector: A México Perspective», paper prepared for the ITF-OECD Round Table on «Improving the Practice of Cost-Benefit Analysis in Transport», Instituto Méxicano de Transporte, Querétaro, México, 21-22 octubre.

[14] SPECTRON DESARROLLO (2009): «Evaluación Socio-Económica de la Línea 12 del Metro de la Ciudad de México», Unidad de Inversiones, Secretaría de Hacienda y Crédito Público, 8 de junio (http://www.apartados.hacienda.gob.mx/sistema_cartera_ inversion/index.html, clave de cartera el codigo 09093110002).

[15] WORLD BANK (2003): Project Appraisal Document, Report No. 24941-CO, Bogota Urban Services Project, February 14.

[16] WORLD BANK (2004): Project Appraisal Document, Report No: 28926-CO, Integrated Mass Transit Systems Project, may 14. 